\title{
A Rare and Severe Case of Split-Hand/Foot Malformation in a Child in India
}

\author{
Sunil H. Shetty, Ravindra G. Khedekar, Mishil Parikh, Nikita Shetty \\ Hospital \& Research Center, Pad. Dr. D. Y. Patil Medical College, Navi Mumbai, India \\ Email: Mishil7@gmail.com
}

Received 19 April 2014; revised 31 May 2014; accepted 17 June 2014

Copyright (C) 2014 by authors and Scientific Research Publishing Inc.

This work is licensed under the Creative Commons Attribution International License (CC BY). http://creativecommons.org/licenses/by/4.0/

c) (i) Open Access

\section{Abstract}

Ectrodactyly, termed Split-Hand/Split-Foot Malformation (SHFM) is a rare genetic condition characterized by defects of the central elements of the autopod (hand/foot). Clinical presentation is with the absence of one or more median rays or digits creating cone shaped clefts of the hands and/or feet. The present case of severe bilateral split-hand and foot malformations was presented in an 8-year-old girl in India. This case of SHFM involves the complete absence of the central rays of the autopod in which each of the hands and each foot is divided into two parts by a coned shape cleft tapering proximally, resembling a "lobster claw". SHFM is often associated with other limb anomalies including monodactyly, syndactyly and aplasia and/or hypoplasia of the phalanges, metacarpals, and metatarsals. Most cases are sporadic; however familial forms do exist with predominantly autosomal dominant inheritance. This case is an example of the non-syndromic form of SHFM expressed with isolated involvement of the limbs, while the syndromic form is associated with anomalies as intellectual disability, ectodermal and craniofacial findings and hearing loss. Non-syndromic isolated ectrodactyly does not usually require surgical intervention. We recommended against surgical reconstruction, due to lack of evidence of functional disability.

\section{Keywords}

Congenital Limb Deformities, Split-Hand/Split-Foot Malformation, Ectrodactyly

\section{Introduction}

Split-hand/foot malformation (SHFM) is a primary structural rare abnormality of the limbs. SHFM or Ectrodactyly is characterized by the absence of one or more median rays or digits creating cone shaped clefts of the hands and/or feet. It is often associated with other limb anomalies including monodactyly, syndactyly and aplasia and/or hypoplasia of the phalanges, metacarpals, and metatarsals. 
Ectrodactyly is an uncommon inborn malformation of the hand where the intermediate digit is missing, and the hand is cleft where the metacarpal of the finger should be. This schism gives the hands the show of lobster claws. Ectrodactyly is also known as Karsch Neugebauer syndrome. It has been called lobster-claw syndrome because the hands of those affected can appear claw-like. This rare syndrome has many forms (Table 1); one of the most common of these forms called Type I is associated with a specific region of human chromosome 7 that contains two homeobox genes, DLX5 and DLX6. These genes are similar to a gene in insects called distal-less that controls limb development. When this gene is defective in the fruit fly the distal part of the insect limb is missing. Ectrodactyly may be present alone, or may be part of a number of birth defects. Hand deformation alone is unlikely to affect health.

We report herein a case of severe SHFM involving all four limbs.

\section{Case Report}

An 8-year-old girl presented with severe bilateral split-hand and foot malformations since birth (Figure 1). Physical examination revealed absence of multiple metatarsals and phalanges with a cone shaped cleft tapering proximally in both the feet and in both the hands. There were no other medical conditions or dysmorphic features. The girl was an only child, born out of a non-consanguineous marriage. The Parents are non-syndromic with no family history of limb malformations. The parents brought their daughter to the medical center for consultation regarding options for treating what they perceived as a cosmetic deformity. Examination showed no functional disability thus surgery was not recommended.

\section{Discussion}

Ectrodactyly, also termed Split-Hand/Split-Foot Malformation (SHFM) is a rare genetic condition characterized by defects of the central elements of the autopod (hand/foot). It has a prevalence of 1:10,000 - 1:90,000 worldwide.

The presented case of severe bilateral SHFM involves the complete absence of the central rays of the autopod

\section{Table 1. Classification for cleft hand described by Manske and Halikis.}

\begin{tabular}{ccl}
\hline Type & Description & Characteristics \\
\hline I & Normal web & Thumb web space not narrowed \\
IIA & Mildly narrowed web & Thumb web space mildly narrowed \\
IIB & Severely narrowed web & Thumb web space severely narrowed \\
III & Syndactylized web & Thumb and index rays syndactylized, web space obliterated \\
IV & Merged web & Index ray suppressed, thumb web space is merged with the cleft \\
V & Absent web & Thumb elements suppressed, ulnar rays remain, thumb web space no longer present \\
\hline
\end{tabular}

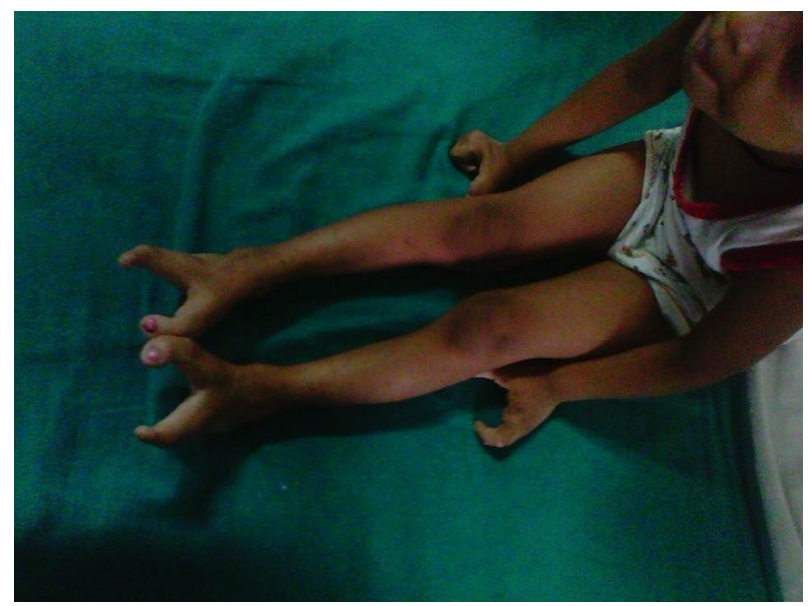

Figure 1. Showing the lobster claws and feet in a Child. 
Table 2. Treatment based on the classification of Manske and Halikis.

\begin{tabular}{cl}
\hline Type & \multicolumn{1}{c}{ Treatment } \\
\hline I/IIA & Reconstruction of the transverse metacarpal ligament \\
IIB/III & Transposition of the index metacarpal with reconstruction of the thumb webspace \\
IV & Mobility and/or position of the thumb of ulnar digit to promote pinch and grasp \\
V & There is no cleft or web space and the thumb is very deficient. This hand requires consideration of creating a radial digit \\
\hline
\end{tabular}

in which each of the hands and each foot is divided into 2 parts by a coned shape cleft tapering proximally, resembling a "lobster claw" [1]. The severity may vary between patients as well as between different limbs of the same individual.

Most cases of SHFM are sporadic as in this case report, however familial forms do exist with predominantly autosomal dominant inheritance. Autosomal-recessive and X-linked forms are rare while some cases of SHFM are due to chromosome deletions and duplications [2].

The main pathogenic mechanism for ectrodactyly development is due to a failure to maintain median apical ectodermal ridge (AER) signaling, either through increased cell death, or through reduced cell proliferation. This AER activity defect does not occur in the very earliest stages of limb development, since that would result in more severe limb malformations that are not limited to the autopod [2].

The syndromic form of SHFM expressed in some patients is associated with anomalies asintellectual disability in 33\%, ectodermal and craniofacial findings in $>35 \%$ and orofacial clefting, and neurosensory hearing loss in $>35 \%$ [3].

The malformation, when non-syndromic can be expressed with isolated involvement of the limbs, as presented in this case. Usually cases of isolated ectrodactyly do not require surgical intervention, as we also recommended against surgical reconstruction, which should be considered only in cases with functional disability. Most individuals adapt well and live normal lives with modest functional impairment of the hands. Thus functional training and physical therapy are advised.

\section{Conclusions}

The diagnosis of ectrodactyly syndrome can be complex because of the overlap of symptoms with other ectodermal dysplasia syndromes. Currently there are several treatments, which can normalize the appearance of the hands, yet they will not function precisely the same way as regularly formed hands. The prognosis for most individuals with ectrodactyly syndrome is very good. Some people with ectrodactyly use prosthetic hands to avoid the rude stares of others. Ectrodactyly is an inherited circumstance which can be treated surgically to better role and show. Early physical and occupational therapy can help those with ectrodactyly adapt, and learn to write, pick things up, and be fully functional. Genetic findings could have great implications in clinical diagnosis and treatment of not only ectrodactyly, but also many other related syndromes.

Surgical treatment of the cleft hand is based on several indications:

Improving function-Absent thumb, Deforming syndactyly (mostly between digits of unequal length like index and thumb), Transverse bones (this will progress the deformity, growth of these bones will widen the cleft), Narrowed first webspace and Esthetical aspects—reducing deformity.

When surgery is indicated, the choice of treatment is based on the classification. Table 2 shows the treatment of cleft hand divided into the classification of Manske and Halikis. Techniques described by Ueba, Miura and Komada and the procedure of Snow-Littler are guidelines, since clinical and anatomical presentation within the types differ, the actual treatment is based on the individual abnormality [4].

\section{References}

[1] \#183600 Split-hand/foot malformation 1; SHFM1, Online Mendelian Inheritance in Man (OMIM) Catalog of Human Genes and Genetic Disorders. http://omim.org/entry/183600

[2] Duijf, P., van Bokhoven, H. and Brunner, H.G. (2003) Pathogenesis of Split-Hand/Split-Foot Malformation. Human Molecular Genetics, 12, R51-R60. http://dx.doi.org/10.1093/hmg/ddg090

[3] Lango Allen, H., Caswell, R., Xie, W., Xu, X., Wragg, C., Turnpenny, P.D., Turner, C.L., Weedon, M.N. and Ellard, S. (2014) Next Generation Sequencing of Chromosomal Rearrangements in Patients with Split-Hand/Split-Foot Malfor- 
mation Provides Evidence for DYNC1I1 Exonic Enhancers of DLX5/6 Expression in Humans. Journal of Medical Genetics, 51, 264-267. http://dx.doi.org/10.1136/jmedgenet-2013-102142

[4] Manske, P.R. and Halikis, M.N. (1995) Surgical Classification of Central Deficiency According to the Thumb Web. Journal of Hand Surgery, 20, 687-697. http://dx.doi.org/10.1016/S0363-5023(05)80293-X 
Scientific Research Publishing (SCIRP) is one of the largest Open Access journal publishers. It is currently publishing more than 200 open access, online, peer-reviewed journals covering a wide range of academic disciplines. SCIRP serves the worldwide academic communities and contributes to the progress and application of science with its publication.

Other selected journals from SCIRP are listed as below. Submit your manuscript to us via either submit@scirp.org or Online Submission Portal.
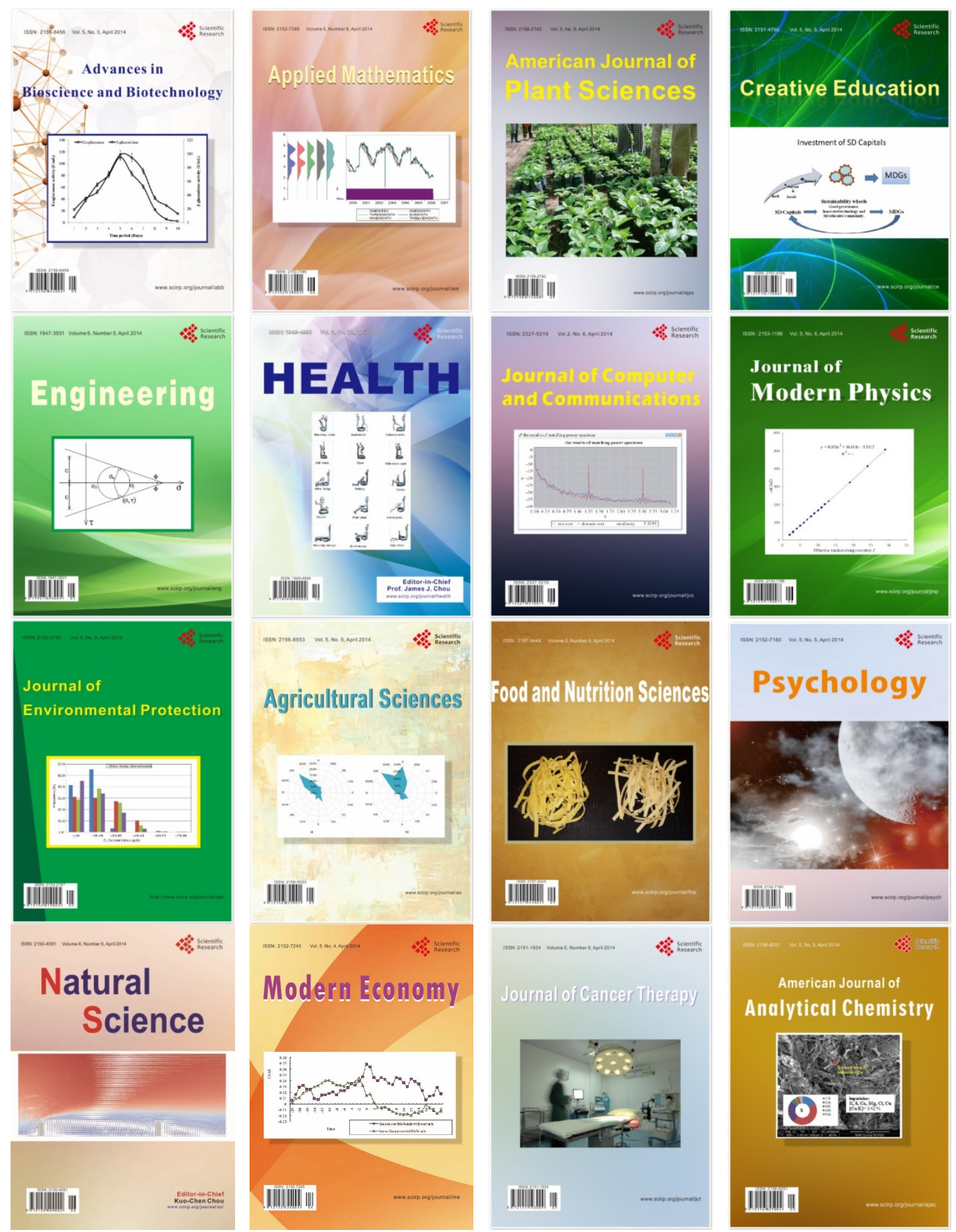